\title{
Revista de la
}

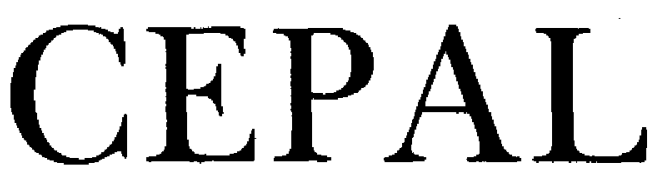

\author{
Secretario Ejecutivo \\ Gert Rosenthal \\ Secretario Ejecutivo Adjunto \\ Carlos Massad
}

\author{
Director de la Revista \\ Aníbal Pinto \\ Secretario Técnico \\ Eugenio Lahera
}

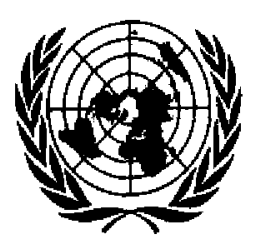

NACIONES UNIDAS

COMISION ECONOMICA PARA AMERICA LATINA Y EL CARIBE

SANTIAGO DE CHILE, DICIEMBRE DE 1992 


\section{Revista de la}

\section{CEPAL}

Santiago de Chile

Diciembre de 1992

Número 48

\section{SUMARIO}

En busca de otra modalidad de desarrollo. Pedro Sainz y Alfredo Calcagno.

El nuevo orden industrial internacional. Michael Mortimore.

La inversión europea en América Latina: un panorama.Juan Alberto Fuentes.

Una evaluación del comercio intraindustrial en la región. Renato Baumann.

Políticas industriales en Centroamérica. Larry Willmore.

Participación y medio ambiente. Tonci Tomic.

Una opción de financiamiento para la provisión de agua y servicios sanitarios. Terence Lee y Andrei Jouravlev.

¿Pensar lo social sin planificación ni revolución? Martín Hopenhayn.

Grecimiento y distribución del ingreso en países de mediano desarrollo. Eduardo Sarmiento.

Política monetaria con apertura de la cuenta de capitales. Roberto Zahler. 


\section{REVISTA DE LA CEPAL Nº 48}

\section{Políticas industriales en Centroamérica}

\author{
Larry Willmore*
}

Los pafses centroamericanos llevan cuatro décadas de cooperacion en virtud de tratados bilaterales y multilaterales, el más importante de los cuales es el Tratado General de Integración Económica Centroamericana, que estableció en 1960 el Mercado Común Centroamericano. Sin embargo, las políticas industriales aplicadas en ellos a partir de entonces se caracterizan por su falta de uniformidad.

Este articulo describe sucintamente las politicas en vigor a mediados de 1992 en cinco paises -Costa Rica, El Salvador, Guatemala, Honduras y Nicaraguaen materia de inversión extranjera, registro de nuevas inversiones, protección arancelaria e incentivos a las exportaciones extrazonales, factores todos que influyen en la competitividad relativa de las empresas industriales de la subregión. Asimismo, pasa revista a otros factores que afectan la capacidad de competencia de estos países, como el costo de la mano de obra, de la energía y del agua.

* Oficial de Asuntos Económicos (Industria y Turismo), en la Subsede de la CEPAL para el Caribe. Fste artículo se basa en un informe del autor para el Proyecto CAM/91/009. ejecutado por la Organización de las Naciones Unidas para el Desarrollo Industrial (ONUDI), con fondos del Programa Es. pecial de Cooperación para Centroamérica (PEC) que administra el Programa de las Naciones Unidas para el Desarrollo (PNUD).

\section{Introducción}

Tradicionalmente, los gobiernos de Centroamérica han seguido políticas de "puertas abiertas" para la inversión extranjera y los países incluso han competido entre ellos con el afán de atraer inversiones foráneas. ${ }^{1}$ Sin embargo, hoy hay diferencias importantes entre ellos en el tratamiento que dan al capital extranjero. De los cinco países analizados, Guatemala es el único que no distingue entre inversión nacional y extranjera. En El Salvador y Honduras se prohíbe la inversión extranjera en pequeña escala. En Nicaragua se imponen algunas restricciones a toda inversión foránea, mientras que en Costa Rica, El Salvador y Honduras se estimula dicha inversión dándole acceso preferencial a divisas al tipo de cambio oficial.

Largos trámites burocráticos pueden obstaculizar tanto la inversión extranjera como la nacional. En Centroamérica el tiempo necesario para el registro de una nueva empresa fluctúa entre dos y tres meses (Costa Rica) y doce meses (Honduras). En Nueva York la misma gestión demora cuatro horas.

En economías pequeñas como las centroamericanas, el arancel externo suele influir más que la estructura del mercado en establecer el tipo de competencia que prevalece, porque es el precio de las importaciones, reales o potenciales, el que determina el precio de las manufacturas locales. Por concentrada que esté la producción en una industria, la posibilidad de importar constituye un medio de regulación, pues inhibe el ejercicio del poder de los productores en el mercado.

En los años sesenta, los cinco países mantenían un solo arancel externo para proteger a las industrias del Mercado Común Centroamericano (MCCA). A finales de 1970, Honduras abandonó el MCCA, negoció tratados bilaterales en reemplazo del multilateral y estableció su propio aran-

${ }^{1}$ Gert Rosenthal (1975, p. 273) notó hace dos décadas que "se ha producido una especie de competencia entre los países para atraer dicho capital, como una manera de mejorar su participación en las exportaciones intrarregionales de artículos manufacturados. De ahí que a nivel macional se siga una política de 'puertas abiertas' a la inversión extranjera directa, con limitadísimos casos de regulación o control de la misma". (El artículo original fue publicado en 1972). Véase también Willmore, 1976. 
cel externo. A mediados de los años ochenta, los cuatro países restantes dejaron de mantener un arancel externo común e iniciaron un proceso unilateral de desgravación arancelaria. Pero recientemente los cinco países acordaron restablecer un arancel externo común que comenzará a regir a principios de 1995. El nuevo instrumento será menos proteccionista que el del pasado, con un piso de $5 \%$ ad valorem y un techo de $20 \%$ ad valorem.

Las restricciones y los impuestos a la importación crean un sesgo antiexportador: los incentivos a la producción para el mercado nacional (o subregional) son mayores que para exportar a terceros países. Todos los países de la subregión. han intentado compensar este sesgo, al menos en parte, mediante la promoción de exportaciones no tradicionales, sobre todo de manufacturas.

La promoción de las exportaciones varía mucho de un país de la subregión a otro, pero en cuatro de ellos hay regímenes de importación temporal, y en todos regímenes de zonas francas industriales y estímulos a los exportadores que producen básicamente para los protegidos mercados locales. Más adelante se resumen tanto las diferencias como las semejanzas entre los cinco países en este campo.

Así como son heterogéneas las políticas de los países centroamericanos en materia de inversión extranjera, inscripción de empresas, protección arancelaria e incentivos a las exportaciones, también lo son los costos de la mano de obra, la energía y el agua. En Costa Rica se pagan los salarios más altos, que casi duplican a los de los otros países. El precio de la electricidad es relativamente uniforme, pero la gasolina es notablemente más cara en Nicaragua y Guatemala, el diesel en Honduras y Guatemala, y el agua potable en Costa Rica y Honduras.

\section{$\stackrel{\text { I }}{\text { Inversión extranjera }}$}

Guatemala no dispone de legislación específica sobre la inversión extranjera en el sector manufacturero; por eso, las empresas de propiedad nacional y extranjera reciben el mismo trato ante la ley. Sin embargo, existe un registro voluntario para empresas de capital estadounidense que deseen acogerse al Convenio sobre Garantías suscrito entre los gobiernos de Guatemala y los Estados Unidos.

En Costa Rica las leyes tampoco discriminan entre empresas nacionales y extranjeras en el sector manufacturero, pero el Banco Central mantiene un registro de inversiones foráneas. Las empresas que voluntariamente registran su capital extranjero tienen acceso a divisas al tipo de cambio oficial para: i) pagar préstamos (intereses y amortización) cuyo plazo no sea inferior a cinco años; ii) repatriar capital (normalmente después de cuatro años, aunque puede hacerse antes); iii) repatriar utilidades, previa declaración para los fines del impuesto sobre la renta; iv) pagar regalías, sujetas a un impuesto de $20 \%$, y v) pagar asistencia técnica, con un impuesto de $30 \%$ y una comisión de $10 \%$. Este acceso a divisas al tipo de cambio oficial es importante cuando existe gran diferencia entre el tipo de cambio bancario y el del mercado "negro" o paralelo. En estas circunstancias, las empresas extranjeras registradas aventajan a las no registradas y a las nacionales, ya que los empresarios nacionales no tienen la opción de registrar sus inversiones. De ahi que las políticas costarricenses -aplicadas por el Banco Central mediante reglamentos internos y no por el Poder Ejecutivo a través de leyes y decretos- resulten discriminatorias, al favorecer la inversión extranjera.

En Honduras una nueva Ley de Inversiones decretada por el Congreso Nacional en junio de 1992 considera que "la inversión extranjera es complementaria de la inversión nacional en el desarrollo económico y requiere de un tratamiento no discriminatorio". Sin embargo, la ley es discriminatoria en dos de sus artículos. Primero, el artículo 20 estipula que "la industria y el comercio en pequeña escala es patrimonio exclusivo de los hondureños y las sociedades mercantiles integradas en su totalidad por hondureños". Aún falta el reglamento que defina lo que se entiende por "pequeña escala", pero la restricción de inversiones extranjeras a la industria grande y mediana tiene importancia potencial. Segundo, el artículo 4 ga- 
rantiza al inversionista el acceso a la compra de moneda extranjera para los siguientes fines: la "importación de aquellos bienes y servicios necesarios para la operación de la empresa, incluyendo el pago de regalías, rentas y asistencia técnica"; el "pago de deudas contraídas en el exterior para las operaciones de la empresa y los intereses devengados por las mismas", y el "pago de los dividendos y la repatriación de capitales sobre las inversiones extranjeras registradas bajo la presente ley".

Aunque este artículo discrimina a favor de la inversión foránea, ya que solamente el extranjero tiene garantizadas divisas para repatriar (o expatriar) su capital y sus ganancias, la ventaja que otorga es mínima, porque en el mismo artículo se garantiza la "apertura de cuentas en moneda extranjera en los bancos del sistema nacional, pudiendo los inversionistas nacionales y extranjeros retirar sus depósitos en forma parcial o total en la misma moneda en que los efectuaron."

Las leyes salvadoreñas, así como la nueva legislación hondureña, combinan restricciones con estímulos a la inversión foránea. La Constitución de 1950 establece que "el comercio y la industria en pequeño son patrimonios de los salvadoreños por nacimiento y de los centroamericanos naturales." El decreto 505 del 15 de diciembre de 1961 (Ley de Protección del Comercio y la Industria en Pequeño) define como "pequeña" a toda empresa con menos de 10000 dólares de capital y prohíbe la inversión de extranjeros salvo en "aquellas industrias [que] ... no sean explotadas por salvadoreños o centroamericanos naturales", en cuyos casos se puede otorgar un permiso válido por 10 años, renovable a su término, siempre y cuando no existan empresas salvadoreñas en la misma actividad.

En la Ley de Fomento y Garantía de la Inversión Extranjera de El Salvador se exige que toda inversión foránea sea registrada en el Ministerio de Economía. Al capital extranjero registrado se le otorgan los beneficios siguientes, no concedidos a empresas nacionales: i) tenencia de cuentas bancarias en moneda extranjera que no pueden ser convertidas a moneda nacional sin autorización del propietario; ii) crédito fiscal para efectos de pago del impuesto sobre la renta, cubierto por la sociedad en la cual se haya efectuado la inversión, y iii) acceso a divisas extranjeras al tipo de cambio oficial para repatriar ganancias, para pagar préstamos extranjeros, así como regalías y asistencia técnica hasta por un $10 \%$ de las ventas netas, y para repatriar capital. Como se puede advertir, estos beneficios son más generosos que los otorgados en Costa Rica y similares a los otorgados en Honduras; en todo caso, su valor para el inversionista depende de que haya una diferencia entre el tipo de cambio oficial y el paralelo. Esta diferencia no existe hoy en El Salvador, pero podría reaparecer en el futuro, lo que daría ventaja a los empresarios extranjeros sobre los salvadoreños.

Actualmente, los extranjeros no pueden invertir legalmente en Nicaragua. Existe un proyecto de ley de inversiones extranjeras que contempla la creación de un comité de inversiones extranjeras, cuya misión sería la de aprobar o rechazar las solicitudes de inversionistas y supervisar su conducta. La Asamblea Nacional aprobó una versión de esta ley el 12 de abril de 1991, la que fue vetada por el Poder Ejecutivo, básicamente porque establecía un comité de inversiones extranjeras con nueve miembros en vez de los cinco que había solicitado el Poder Ejecutivo. A juicio de éste, un comité en el que participen el Ministro del Trabajo, el Director del Instituto Nicaragüense de Recursos Naturales y del Ambiente, un miembro de la Cámara de Industrias y el alcalde del municipio donde se ubique la inversión, dificulta la aprobación de una solicitud. Con esta ley, los principales beneficios para un inversionista, una vez aprobado su plan de inversión, serán: i) "indemnización rápida, adecuada y efectiva en caso de expropiación", y ii) acceso a divisas al tipo de cambio oficial para repatriar ganancias y, después de tres años, capital. Además, el comité de inversiones extranjeras "podrá eximir total o parcialmente el pago de impuestos fiscales y aduaneros". En cambio, el inversionista extranjero estará obligado a convertir las divisas que reciba de sus exportaciones en moneda nacional, al tipo de cambio oficial.

En síntesis, en Costa Rica, El Salvador y Honduras se estimula la inversión extranjera otorgándole acceso preferencial a divisas al tipo de cambio oficial, aunque en El Salvador y Honduras se excluye al extranjero de la pequeña industria. En Guatemala se da al inversionista extranjero igual tratamiento que al nacional, mientras que en $\mathrm{Ni}$ caragua se le imponen algunas restricciones. 


\section{II \\ Formación de nuevas empresas}

Las nuevas inversiones significan creación de nuevas empresas o ampliación de las existentes. La burocracia estatal puede obstruir este proceso haciendo costoso y lento el registro de nuevas empresas. Hernando de Soto, autor del ya famoso libro El otro sendero, cita en otras de sus obras (De Soto, 1992), como una de las causas del subdesarrollo de su país, el hecho de que "en el Perú, una persona tardaba 289 días en registrar una empresa frente a las cuatro horas que necesitan en la ciudad de Nueva York."

En este aspecto, Centroamérica se sitúa cerca del Perú y muy lejos de Nueva York. En Honduras, el tiempo mínimo para registrar una nueva empresa es de doce meses, y en Guatemala de diez a doce meses. En ambos países, si una empresa desea ampliar su capital social, el trámite burocrático es casi tan largo y costoso como lo es formar una nueva empresa. La barrera que enfrenta el inversionista en El Salvador y Costa Rica es menor, ya que estos países permiten el registro de sociedades anónimas de capital variable. Los trámites burocráticos requieren "sólo" de cuatro a cinco meses en El Salvador y de dos a tres meses en Costa Rica. No disponemos de información sobre los trámites para registrar empresas o inversiones en Nicaragua.

Algunos gobiernos centroamericanos están conscientes de que los trámites burocráticos desalientan la inversión, y están intentando simplificar el sistema. El congreso guatemalteco acaba de emitir una ley creando una "ventana única" para el inversionista. La Ley de Inversiones en Honduras pretende hacer lo mismo.

\section{III \\ Protección contra las importaciones}

Durante más de tres décadas, en los países de Centroamérica se siguió una estrategia de desarrollo "hacia adentro". En consecuencia, se aplicaron aranceles altos a los bienes de consumo final y se exoneró la importación de maquinaria, materia prima y bienes intermedios para uso de las industrias manufactureras.

Hoy día en los países centroamericanos se han eliminado todas las exoneraciones arancelarias y todos los aranceles específicos (por peso o unidad), y están bajando paulatinamente los aranceles ad valorem sobre la importación de bienes que compiten con la industria local. Esta reforma arancelaria empezó en 1986 en Costa Rica, El Salvador y Guatemala, en 1987 en Nicaragua y en 1990 en Honduras. En los cinco países se han tomado muchas medidas unilaterales, pero se ha asumido el compromiso de volver a un arancel externo común dentro de dos años y medio. ${ }^{2} \mathrm{El}$ nuevo arancel centroamericano será menos pro- teccionista que el del pasado. Habrá sólo cuatro tasas: $5 \%$ para maquinaria, materias primas y bienes intermedios no producidos en la subregión; $10 \%$ para maquinaria, materias primas y bienes intermedios producidos en la subregión; $15 \%$ para bienes de consumo final no producidos en la subregión, y $20 \%$ para bienes finales producidos en la subregión.

La protección arancelaria que rige en los cinco países y los niveles previstos para 1993, 1994 y 1995 se presentan en el cuadro 1. El arancel máximo, que sería de $20 \%$ en 1995 , no

${ }^{2}$ Los presidentes centroamericanos, en el punto 28 de la Declaración de San Salvador, del 17 de julio de 1991, prometieron instrumentar el 31 de diciembre de 1992 un arancel uniforme centroamericano con un "techo de $20 \%$ y un piso no menor de $5 \%$ "; pero los países pueden definir "una lista reducida de productos que alcanzarán los niveles acordados a más tardar el 31 de diciembre de 1994, para los cuales se establecerá un programa de desgravación". 
impide la imposición de tasas mayores que graven el consumo por razones fiscales o de salud. Los cigarrillos y los perfumes, por ejemplo, podrían pagar un arancel de $100 \%$; pero de ser producidos localmente para el mercado interno pagarán impuestos de $80 \%$ sobre su valor puesto en fábrica. Esto asegurará que los altos gravámenes cobrados en la aduana no se conviertan en aranceles de alta protección. ${ }^{8}$
Costa Rica mantiene actualmente aranceles que van desde el $5 \%$, aplicado a la maquinaria y los repuestos, hasta el $46 \%$ para "rubros sensitivos" (textiles y calzado). El gobierno mantiene, por razones fiscales, un "piso" arancelario de $10 \%$ para la importación de materia prima y bienes intermedios. Este coloca a la industria costarricense en desventaja competitiva frente a productores del resto de Centroamérica; sin embargo,

Cuadro 1

CINCO PAISES CENTROAMERICANOS: ARANCELES DE IMPORTACION

(Porcentajes)

\begin{tabular}{lllll}
\hline & 1992 & 1993 & 1994 & 1995 \\
\hline Costa Rica & 5 a $46^{\mathrm{a}}$ & 5 a 40 & 5 a 31 & 5 a 20 \\
El Salvador & 5 a 30 & 5 a 25 & 5 a 20 & 5 a 20 \\
Guatemala & 5 a $30^{\mathrm{b}}$ & 5 a 20 & 5 a 20 & 5 a 20 \\
Honduras & 5 a $35^{c}$ & 5 a 20 & 5 a 20 & 5 a 20 \\
Nicaragua & 5 a $60^{\text {d }}$ & 5 a 20 & 5 a 20 & 5 a 20 \\
\hline
\end{tabular}

Fuente: Secretaría Permanente del Tratado General de Integración Económica Centroamericana (SIECA), Políticas económicas vigentes en los paises centroamericanos a thero de 1992, Guatemala, febrero de 1992, e información proporcionada por los ministerios de econotmía de cada país.

* En marzo de 1992 se eliminó una sobretasa temporal de dos puntos porcentuales para importaciones extrarregionales . El Banco Central de Costa Rica exigió depósitos previos hasta finales de 1991.

' Incluye una sobretasa de tres puntos porcentuales sobre las importaciones extrarregionales.

- Incluye una sobretasa general (excepto para maquinaria y equipos) de cinco puntos porcentuales, y una adicional de diez puntos porcentuales para productos finales.

- Incluye impuestos selectivos de consumo de hasta 40 puntos porcentuales, que funcionan como aranceles de importación.

la situación está mejor que la que se presentó en 1991, cuando el "piso" de 10\% se aplicó también a la maquinaria y los repuestos, y se cobró además una sobretasa de 10 puntos porcentuales a

${ }^{3}$ El punto $28(2)$ de la Declaración de San Salvador permite la elaboración de "una lista limitada de excepciones de bienes de carácter fiscal que podrán tener un arancel superior a $20 \%$ ". Si la producción local (actual o potencial) está exenta del pago de los aranceles excepcionales, el resultado podría ser el fomento de la producción de estos "bienes de carácter fiscal" con la consiguiente pérdida de ingresos fiscales. toda importación extrarregional. Cabe esperar que al final de 1994 rija un arancel meta con tasas ad valorem de entre $5 \%$ y $20 \%$.

En El Salvador, actualmente los aranceles de importación se hallan entre el $5 \%$ y el $25 \%$, excepto para los textiles y el calzado de cuero, que soportan tasas hasta de 30\%. A mediados de 1993 la tasa máxima bajará a $20 \%$ (25\% para textiles y calzado). En junio de 1994 todos los aranceles se situarán entre el $5 \%$ y el $20 \%$. El gobierno salvadoreño no aplica cuotas, sobretasas ni exigencias de depósito previo a las importaciones, y mantiene un tipo de cambio único y libre. 
En Guatemala, la estructura arancelaria es muy parecida a la salvadoreña. Al presente, las tasas oscilan entre $5 \%$ y $30 \%$ (incluida una sobretasa de tres puntos porcentuales) y el ministro de economía tiene programado bajarlas a un máximo de $20 \%$ al principio de 1993.

En Honduras los aranceles legales ya están entre el $5 \%$ y el $20 \%$. Sin embargo, se aplican sobretasas de cinco puntos porcentuales a las importaciones de cualquier bien (excepto bienes de capital), y de 10 puntos adicionales a los bienes de consumo final. En efecto, los productores de Honduras, igual que los de Costa Rica, pagan un arancel mínimo de $10 \%$ para la importación de materias primas y bienes intermedios. No se sabe aún con certeza cuando se eliminará el cobro de sobretasas a las importaciones, pero se supone que esto sucederá en 1993.

Algunos gobiernos hondureños, a semejanza de otros en la subregión, han utilizado en ocasiones licencias o permisos de importación y exportación para proteger a ciertos productores o favorecer a los consumidores, Es interesante notar que el actual gobierno, en el artículo 4 de la Ley de Inversiones, garantiza al empresario "libertad en la importación y exportación de bienes y servicios sin requerimientos de autorizaciones o permisos administrativos previos" y promete respetar "la libre determinación de precios de los productos o servicios que ofrece."

Nicaragua redujo el arancel máximo en 1990 a $20 \%$. Simultáneamente introdujo numerosos "impuestos selectivos de consumo". Muchos de ellos, como los cobrados a licores, cigarrillos, bebidas gaseosas y cervezas, son efectivamente impuestos de consumo, porque gravan tanto el producto nacional como el importado. Otros, sin embargo, son en realidad "sobretasas selectivas a los aranceles" porque el producto nacional está exento del impuesto. Estos "aranceles disfrazados" se cobran sobre importaciones de cualquier origen (aun de Centroamérica) y agregan hasta 40 puntos porcentuales (como sucede con las galletas finas) al arancel legal. De todos modos, se trata de una medida transitoria: cada seis meses los "impuestos selectivos" bajan, y todos desaparecerán en enero de 1993.

\section{Incentivos para las exportaciones}

La protección de los mercados nacionales o del subregional crea dos tipos de sesgo antiexportador. El primero viene del hecho de que la maquinaria, los equipos, la materia prima y los bienes intermedios se compran a un precio más alto que el de los mismos bienes en el mercado internacional; mientras más alto es el "piso" arancelario, más elevado resulta el costo de estos insumos para el exportador actual o potencial. El segundo sesgo deriva del hecho de que un producto vale más en el mercado local protegido que en los competitivos mercados de exportación, por lo que resulta más atractivo sustituir las importaciones que exportar. Por ambas razones, el volumen de exportaciones resulta menor que el que se observaría en un régimen de libre comercio.

\section{Zonas francas}

La creación de zonas francas industriales es una manera de eliminar en gran parte este sesgo antiexportador, al menos para las empresas que allí se instalan. Hay zonas francas en cada uno de los cinco países, aunque en Honduras las llaman "zonas procesadoras para las exportaciones". En Nicaragua no hay legislación actualizada ni inversiones recientes en este campo, pero existe una zona franca constituida antes de la Revolución Sandinista y que ahora es administrada por un organismo del gobierno, la Corporación Industrial del Pueblo (COIP).

Las empresas instaladas en estos enclaves especiales llamados "zonas francas" laboran habitualmente como si estuvieran en un régimen de libre comercio, con facultad de comprar sus insumos en cualquier parte del mundo, manejar sus cuentas en las divisas que deseen y exportar sus productos a otros países. Además, disfrutan de otros privilegios, como la reducción de impuestos y la ausencia de los reglamentos que afectan a la industria en el resto del país. La clave del éxito de una zona franca es la libre importación de insumos, con la condición de que éstos se reexporten o se 
transformen en productos para la exportación. Como bien explica un estudioso de las zonas francas (Warr, 1989, p. 34), "aunque los detalles ... varían, una característica universal es la ausencia casi por completo de gravámenes o de reglamentaciones de importación de bienes intermedios a las zonas".

La legislación costarricense se aleja de esta "característica universal" de las zonas francas porque el gobierno protege a los productores de insumos, permitiéndoles presentar sus quejas a la Dirección General de Industria. Si esta entidad determina que los productores nacionales pueden igualar las importaciones en términos de precio, calidad y tiempo de entrega, la empresa de la zona franca tendrá que "dar prioridad" al uso de los insumos nacionales.

Con estas restricciones, Costa Rica se aparta del resto del mundo en cuanto a legislación sobre zonas francas. Los empresarios que eligen instalar su planta en una zona de esa índole están motivados, principalmente, por la posibilidad de aumentar su competividad al quedar fuera de la jurisdicción aduanera del país, y poder comprar en cualquier parte del mundo materia prima y bienes intermedios de la calidad deseada y a los mejores precios. Si en Costa Rica se aplicara la legislación al pie de la letra, la competitividad de esas empresas se vería perjudicada, Y si no se pretende aplicar la ley, sería preferible modificarla para no desanimar a los inversionistas. La legislación es totalmente prescindible, porque ninguna empresa va a importar insumos si puede conseguirlos localmente en las mismas condiciones.

Todos los gobiernos de la subregión eximen a las empresas en las zonas francas del $100 \%$ de los impuestos sobre las ganancias (cuadro 2). Muchos imponen un límite de 10 o 12 años a estas exenciones, el que suele no ser respetado en la práctica. Las empresas que se instalan en zonas francas son internacionalmente móviles (footloose): las que dejan de producir en un país suelen migrar a una zona franca en otro país donde las condiciones sean más favorables. Así, la exención del pago del impuesto sobre las ganancias de estas empresas es casi siempre prorrogada al final del período inicial. También se las exime, por lo menos en parte, de gravámenes menores como los impuestos territoriales y los impuestos sobre el capital instalado.

\begin{tabular}{|c|c|c|c|c|}
\hline & Costa Rica & El Salvador & Guatemala & Honduras \\
\hline \multicolumn{5}{|l|}{ Exoneración de impuestos } \\
\hline Importación de maquinaria e insumos & $100 \%^{a}$ & $100 \%$ & $100 \%$ & $100 \%$ \\
\hline Ganancias & $\begin{array}{l}100 \%, 8 \text { años } \\
50 \%, 4 \text { años }\end{array}$ & $\begin{array}{l}100 \%, 10 \text { años, } \\
\text { prorrogable }\end{array}$ & $100 \%, 12$ años & $100 \%$ \\
\hline Ventas al mercado local & $\begin{array}{l}\text { Hasta } 40 \% \text {, } \\
\text { sujeto a } \\
\text { aprobación }\end{array}$ & $\begin{array}{l}\text { Sin limite, } \\
\text { sujeto a } \\
\text { aprobación }\end{array}$ & $\begin{array}{l}\text { Hasta } 20 \% \text {, } \\
\text { sujeto a } \\
\text { aprobación }\end{array}$ & $\begin{array}{l}\text { Sin límite } \\
\text { "cuando no } \\
\text { haya produc- } \\
\text { ción nacio- } \\
\text { nal de las } \\
\text { mismas" } \\
\text { sujeto a } \\
\text { aprobación }\end{array}$ \\
\hline
\end{tabular}

Fuente: Leyes de cada país.

- Normalmente no hay restricciones para importaciones a la zona, pero se puede llegar a testringir las de materia prima o insumos si la Dirección General de Industria determina que productores nacionales pueden satisfacer las condiciones de precio, calidad y plazo de entrega requeridas por las empresas importadoras. 
Las empresas de zonas francas reciben sus privilegios con la condición de que exporten su producción, que ésta se utilice dentro de la zona o que se reexporten todos los productos importados. Sin embargo, las leyes de la subregión permiten la venta de parte de la producción a compradores en el territorio nacional, sujeta, desde luego, al pago de la totalidad de los aranceles correspondientes. En Guatemala se permite la venta de hasta un $20 \%$ de la producción en el mercado local, y en Costa Rica, hasta un $40 \%$. En El Salvador y en Honduras, la ley no fija límites, pero las ventas al mercado nacional deben ser aprobadas siempre por las autoridades gubernamentales (cuadro 2).

Un requisito que hace menos atractiva una zona franca para las empresas es el de que se instalen físicamente en un área determinada. Sin embargo, los países se muestran flexibles ante situaciones de esta índole. Actualmente, de las casi 100 empresas que operan en las zonas francas de Costa Rica, dos tercios han construido "plantas satélites" fuera del área física de la zona franca, debido a dificultades en la contratación de mano de obra o, en algunos casos, a problemas de contaminación ambiental que justifican alejarse de otras plantas industriales. En El Salvador, el Decreto $\mathrm{N}^{2} 461$ del 15 de marzo de 1990 , es más explícito; de hecho, constituye una Ley del Régimen de Zonas Francas y Recintos Fiscales según la cual las "empresas que exporten la totalidad de su producción ... y que por razones técnicas no estén ubicadas en zona franca, podrán solicitar que su establecimiento sea declarado recinto fiscal ..."(artículo 20), y los exportadores que operen en recinto fiscal disfrutarán de los mismos incentivos fiscales que aquellos que operan en zona franca (artículo 22).

\section{Importación temporal}

El régimen de importación temporal tiene cierta ventaja sobre el de zonas francas en cuanto permite la instalación en cualquier parte del país de plantas que ensamblan o "maquilan" insumos importados para la exportación, lo que permite aprovechar la infraestructura existente, sin necesidad de inversiones costosas en nuevos parques industriales. Este régimen es similar al de "recintos fiscales" de El Salvador, pero mucho más flexible. El industrial tiene que garantizar que los insumos importados temporalmente se exportarán dentro de un plazo determinado, normalmente de un año. No hay ninguna otra restricción en la subregión para importaciones de esta índole. Con excepción de El Salvador, los países permiten también la importación sin impuestos de maquinaria y equipos. Igual que para las empresas en zona franca, cada país exonera esta actividad del pago del impuesto sobre las ganancias (cuadro 3).

Cuadro 3

CUATRO PAISES CENTROAMERICANOS: REGIMENES DE IMPORTACION TEMPORAL (MAQUILA, REINTEGRO)

\begin{tabular}{|c|c|c|c|c|}
\hline & Costa Rica & El Salvador & Guatemala & Honduras \\
\hline \multicolumn{5}{|l|}{ Exoneración de impnestos } \\
\hline Importación de maquinaria & $100 \%$ & - & $100 \%$ & $100 \%$ \\
\hline Importación de insumos & $100 \%$ & $100 \%$ & $100 \%$ & $100 \%$ \\
\hline Ganancias & $100 \%^{a}$ & $\begin{array}{l}100 \%, 10 \text { años, } \\
\text { prorrogable }\end{array}$ & $\begin{array}{l}100 \% \\
10 \text { años }\end{array}$ & $\begin{array}{l}100 \% \\
10 \text { años }\end{array}$ \\
\hline Ventas al mercado local & No & $\begin{array}{l}\text { Sin limite, con solo pagar los } \\
\text { impuestos correspondientes }\end{array}$ & $\begin{array}{l}\text { Sin limite, con sólo pagar los } \\
\text { impuestos correspondientes }\end{array}$ & No \\
\hline Incentivos para las exportaciones & No & $\begin{array}{l}\text { Reintegro de } 8 \% \text { del } \\
\text { valor agregado }\end{array}$ & No & No \\
\hline
\end{tabular}

Fuente: Leyes de cada país.

En el caso de inversiones extranjeras registradas, al repatriar las ganancias se cobra un impuesto de $15 \%$. 
Las ventas al mercado local están prohibidas para plantas que operan con el régimen de importación temporal en Costa Rica y Honduras. El Salvador y Guatemala permiten ventas sin límites y sólo exigen el pago de los impuestos arancelarios vigentes que afectan al producto final. El maquilador en El Salvador recibe además un bono de $8 \%$ del valor agregado, pero sólo cuando exporta su producción fuera de la subregión. En Nicaragua no hay por el momento legislación explícita para esta actividad, ni proyecto de ley alguno al respecto.

Universalmente, la importación temporal ha sido concebida para apoyar a los exportadores que utilizan muchos insumos importados con poco valor agregado nacional, pero las leyes de los países de la subregión no definen con claridad los requisitos para hacer uso de este régimen. Una manera de definir si una actividad es o no de maquila es determinar qué porcentaje del valor agrega esta actividad al producto. En Guatemala, el Decreto $\mathrm{N}^{2}$ 29-89 define la actividad de maquila "como aquella orientada a la producción $\mathrm{y} / \mathrm{o}$ ensamble de bienes, que ... contengan como mínimo el cincuenta y uno $(51 \%)$ por ciento de mercancías extranjeras", es decir, un máximo de $49 \%$ de valor agregado nacional. Pero la diferencia entre las actividades que son de maquila y las que no lo son carece de importancia en Guatemala, porque cualquier empresa puede aprovechar los beneficios del régimen de admisión temporal.

\section{Incentivos generales}

Las empresas que producen en zonas francas o con regímenes de importación temporal lo hacen casi exclusivamente para la exportación. Aun cuando se le permita vender en el mercado local, el productor enfrenta aranceles iguales a los que gravan a una fábrica localizada en el extranjero. La gran mayoría de las empresas industriales de Centroamérica produce para el protegido mercado local, y algunas de ellas tienen la posibilidad de exportar al menos una parte de su producción. Existe legislación más flexible para estos "exportadores parciales" en cada país de la subregión.

El cuadro 4 resume los incentivos para la exportación de manufacturas no tradicionales en cada uno de esos países. Estos incentivos no se aplican a exportaciones destinadas a países de la subregión, pero sí a las que se realizan a empresas en zonas francas. La legislación salvadoreña es, sin duda, la más simple: consiste en otorgar en efectivo el " $8 \%$ del valor libre a bordo o valor f.o.b. como compensación, tanto sobre los impuestos de importación como de otros indirectos generados por la actividad exportadora" (artículo 3 del Decreto $\mathrm{N}^{2} 460$ del 15 de marzo de 1990). Esta simplicidad es su principal virtud, porque facilita los trámites burocráticos. Además, con este sistema El Salvador incentiva a los exportadores sin liberarlos del pago de aranceles de importación, estimulando así el uso de insumos nacionales. Sin embargo, el sistema tiene una desventaja: como no todos los insumos pagan el mismo arancel ni toda producción enfrenta el mismo sesgo antiexportador, la tasa de compensación única puede ser excesiva para unas actividades e insuficiente para otras.

Los demás países ofrecen diversos estímulos a sus exportadores. Todos permiten la importación libre de impuestos de maquinaria, equipos e insumos utilizados en la producción de bienes para los mercados de exportación. También en todos se exonera a las empresas, aunque en diferente medida, del pago de impuestos sobre las ganancias generadas por la actividad exportadora. En Nicaragua sólo se las exime del $80 \%$ de los impuestos; en Guatemala y Honduras se limita la exoneración a 10 años.

En Costa Rica, desde 1972, se otorgan Certificados de Abono Tributario (CATs) que originalmente valían $15 \%$ del valor fob (valor puesto en el barco o avión sin flete ni seguros) de las exportaciones no tradicionales. Como este estímulo resultó muy costoso para el Estado, el gobierno decidió eliminar gradualmente la emisión de CATs en los próximos años. ${ }^{4}$ Actualmente Costa Rica ofrece CATs de $8 \%$ del valor fob de las exportaciones cuando el valor agregado nacional es de $35 \%$ a $40 \%$, e incrementos de $1 \%$ por cada cinco puntos adicionales de valor agregado, hasta un máximo de $12 \%$ para exportaciones que incorporan $55 \%$ o más de valor agregado nacional. En Nicaragua se

\footnotetext{
${ }^{4}$ Hoffmaister (1992) calcula que entre 1984 y 1989 cada dólar gastado en CATs generó 1.34 dólares en exportaciones brutas, y 80 centavos de dólar en insumos importados que se incorporaron en los bienes exportados. Así, un dólar en subsidios generó, en promedio, exportaciones netas de solamente 54 centavos, En este período la mayoría de las exportaciones no tradicionales recibió CATs de $15 \%$, sujetos solamente al requisito de un mínimo de $35 \%$ de valor agregado nacional.
} 
ofrece un CAT del $15 \%$ del valor fob de las exportaciones, cualquiera sea el valor agregado nacional de ellas. Esto podría significar un estímulo excesivo para las actividades de ensamblaje o maquila, pero sólo transitoriamente, ya que bajará a $10 \%$ en 1993 , $5 \%$ en 1995 y a cero en 1997.

Cuadro 4

CINCO PAISES GENTROAMERICANOS: INCENTIVOS PARA LAS EXPORTACIONES DE MANUFACTURAS NO TRADICIONALES

\begin{tabular}{|c|c|c|c|c|c|}
\hline & Costa Rica & El Salvador & Guatemala & Honduras & Nicaragua \\
\hline \multicolumn{6}{|l|}{ Exoneración de impuestos } \\
\hline Importación de maquinaria e insumos & $100 \%$ & - & $100 \%$ & $100 \%$ & $100 \%$ \\
\hline Ganancias & $100 \%^{2}$ & - & $100 \%, 10$ años & $100 \%, 10$ años & $80 \%$ \\
\hline Impuestos a las exportaciones & - & - & $1.5 \%$ & $1 \%$ & - \\
\hline Certificado de abono tributario (CAT) & $\begin{array}{l}\text { Hasta } 12 \% \text { del } \\
\text { valor fob }\end{array}$ & - & - & - & $\begin{array}{r}15 \% \text { del } \\
\text { valor fob }\end{array}$ \\
\hline Reintegro en efectivo & - & $\begin{array}{l}8 \% \text { del } \\
\text { valor fob }\end{array}$ & - & - & - \\
\hline Requisitos & \multicolumn{2}{|c|}{$\begin{array}{l}\text { Mínimo } 35 \% \text { de valor } \\
\text { agregado nacional }\end{array}$} & - & $\begin{array}{l}\text { Proporcionar } \\
\text { por lo menos } \\
25 \text { empleos } \\
\text { directos }\end{array}$ & $\begin{array}{l}\text { Exportar por lo } \\
\text { menos } 25 \% \text { de } \\
\text { su producción }\end{array}$ \\
\hline
\end{tabular}

Fuente: Leyes de cada pais.

* En el caso de inversiones extranjeras registradas, al repatriar las ganaricias se cobra un impuesto de $15 \%$.

- Baja cada año y desaparecerá en el año 1997.

- Bajará a $10 \%$ en 1993, a $5 \%$ en 1995 y desaparecerá en 1997.

Guatemala y Honduras son los únicos países de la subregión que no ofrecen a los exportadores de manufacturas ni bono en efectivo ni certificado de abono tributario. Además, son los únicos en gravar estas exportaciones. El impuesto es pequeño ( $1.5 \%$ y $1 \%$ del valor, respectivamente), pero su existencia no ayuda a eliminar el sesgo antiexportador, ya que deja abierta la posibilidad de un alza de la tasa en algún momento futuro.

Dos de los países -El Salvador y Guatemalaofrecen incentivos a todos los exportadores de manufacturas no tradicionales, por pequeño que sea el volumen de las exportaciones o el porcentaje de valor agregado nacional. El Salvador, en la misma ley de reactivación de las exportacio- nes, ofrece incentivos hasta a los exportadores de productos tradicionales (definidos como café, azúcar y algodón) si los someten a un proceso de transformación que agregue un mínimo de $30 \%$ de valor agregado nacional. En Costa Rica se exige que las exportaciones tengan un mínimo de $35 \%$ de valor agregado nacional para recibir incentivos en la forma de CAT. Honduras limita los beneficios a empresas relativamente grandes, con la exigencia de que las exportaciones proporcionen por lo merios 25 empleos directos. En Nicaragua, algunos exportadores potenciales no reciben estímulo, porque los incentivos son sólo para aquellas empresas que exportan el $25 \%$ o más de su producción. 


\section{V \\ Costo de la mano de obra, la energía y el agua}

Los salarios mínimos vigentes en cada país centroamericano se indican en el cuadro 5 junto con las prestaciones sociales que encarecen la mano de obra. Conviene destacar que el concepto de salario mínimo se refiere al sector industrial en su totalidad, y no a empresas específicas. Numerosas empresas, sobre todo las grandes, y las que exportan gran parte de su producción, pagan salarios más altos, pero también contratan personal más capacitado o con mayores posibilidades de capacitarse.
Es interesante advertir la gran dispersión de salarios y de prestaciones sociales en Centroamérica. Los salarios más altos son los de Costa Rica, alrededor del doble de los de los otros cuatro países. Las vacaciones anuales establecidas por ley son relativamente generosas ( 30 días) en $\mathrm{Ni}$ caragua y los feriados (17 días) también. Las prestaciones totales como porcentaje del salario base son más altas en Nicaragua (64\%) que en cualquier otro país, debido en parte a la costumbre

Cuadro 5

CINCO PAISES CENTROAMERICANOS: COSTO DE LA MANO DE OBRA, LA ENERGIA Y EL AGUA

\begin{tabular}{|c|c|c|c|c|c|}
\hline & & El & & & \\
\hline & Costa Rica & Salvador & Guatemala & Honduras & Nicaragua \\
\hline $\begin{array}{l}\text { Salario mínimo mensual } \\
\text { (dólares) }\end{array}$ & 153.31 & 83.00 & 68.00 & $85.00^{\circ}$ & 76.00 \\
\hline Seguro social (\%) & 14.0 & 13.25 & 10.0 & 7.0 & 12.0 \\
\hline Otros impuestos $(\%)$ & 8.0 & - & 1.3 & 1.0 & 2,0 \\
\hline $\begin{array}{l}\text { Feriados pagados } \\
\text { (días/año) }\end{array}$ & 6 & 11 & 12 & 11 & $17^{\circ}$ \\
\hline Vacaciones pagadas & 15 & $15^{\mathrm{d}}$ & 15 & $10^{\mathrm{e}}$ & 30 \\
\hline Aguinaldo anual (días) & 30 & $10^{r}$ & 30 & 30 & 30 \\
\hline Canasta de alimentos (\%) & - & - & - & - & 26.3 \\
\hline Total prestaciones (\%) & 36.7 & 26.6 & 28.5 & 27.3 & 64.2 \\
\hline Costo total por mes (dólares) & 209.57 & 105.08 & 87.38 & 108.20 & 124.79 \\
\hline Semana laboral (horas) & 48 & 44 & 44 & 44 & 48 \\
\hline Costo total por hora (dólares) & 1.02 & 0.56 & 0.46 & 0.57 & 0.60 \\
\hline Tipo de cambio por dólar & 138.30 & 8.10 & 5.09 & 5,40 & 5.00 \\
\hline Electricidad (dolar $/ \mathrm{kWh})^{\mathrm{g}}$ & 0.06 & 0.05 & 0.07 & 0.05 & 0.06 \\
\hline Gasolina regular (dólar/galón) & 1.29 & 1.45 & 1.76 & 1.32 & 1.90 \\
\hline Diesel (dolar/galón) & 1.09 & 0.87 & 1.17 & 1.19 & 1.10 \\
\hline Agua potable (dólar $/ \mathrm{m}^{3) ~ h}$ & 0.60 & 0.08 & 0.11 & 0.31 & 0.10 \\
\hline
\end{tabular}

Fuente: Secretaria Permanente del Tratado General de Integración Económica Gentroamericana (SIECA), Precios que inciden en los coslos de producción del sector industrial de los paises del istmo centroamericano a enero de 1992, Guatemala, febrero de 1992, e investigación propia.

- Los datos corresponden a] principio de 1992.

- Salario mínimo legal para empresas con más de 15 empleados; para aquéllas con 6 a 15 empleados, el salario mínimo es $14 \%$ más bajo; para aquéllas hasta con cinco empleados, es $30 \%$ más bajo.

- Solamente en Managua; en el resto de Nicaragua son 15 los días feriados pagados por ley.

d I as vacaciones anuales requieren de un pago adicional de $30 \%$ del salario correspondiente

- Para empleados con menos de dos años laborados; con dos años las vacaciones pagadas son de 12 días; con tres años son de 15 días, y con cuatro años o más, de 20 días.

Este es el bono anual para personas con menos de tres años laborados; para las personas con 3 a 10 años o más laborados, el bono es de 15 dfas de salario; para las personas con 10 años en adelante, el bono legal es de 18 días de salario,

s Promedio aproximado para uso industrial.

h Costo en la ciudad capital de cada país. 
de entregar a los operarios cada mes una canasta familiar de productos básicos; las más bajas corresponden a Honduras y El Salvador (27\%).

Hay un costo adicional cuando una empresa despide una persona por razones ajenas a su comportamiento, lo cual no está incluido en los cálculos del cuadro 5 . En cada país centroamericano, estas prestaciones legales son de un mes de salario por cada año trabajado.

El costo de la energía y el agua afecta, al igual que el costo de la mano de obra, la competitividad de la industria manufacturera en Centroamérica. Las tarifas eléctricas difieren poco entre un país y otro, pero son más altas en Guatemala, seguidas de las de Costa Rica y Nicaragua. Empresas con alto consumo de electricidad pagan menos por $\mathrm{kWh}, \mathrm{y}$ aquellas con poco consumo pagan mucho más que los promedios indicados en el cuadro 5. También es importante destacar que en el precio no se considera el costo de las interrupciones de la electricidad, que son frecuentes en El Salvador y Nicaragua. El precio de la gasolina es notablemente más alto en Nicaragua y Guatemala, el del diesel en Honduras y Guatemala y el del agua potable en Costa Rica y Honduras.

\section{Bibliografia}

De Soto, Hernando (1992): Para hacer empresa en democracia, Revista INCAE vol. 5, N², Costa Rica, Instituto Centroamericano de Administración de Empresas (INCAE).

Hoffmaister, Alexander (1992): The cost of export subsidies: evidence from Costa Rica, IMF Staff Papers, vol, 39, N²1, Washington, D.C., Fondo Monetario Internacional (FMI), marzo.

Rosenthal, Gert (1975): Algunos apuntes sobre el grado de participación de la inversión extranjera directa en el proceso de la integración centroamericana, en Eduardo Lizano (ed.), La integración económica cenlroamericana, Lecturas 13, tomo I, México, D.F., Fondo de Cultura Económica.

SIECA (Secretaría Permanente del Tratado General de Inte- gración Económica Centroamericana) (1992a): Políticas económicas vigentes en los paises centroamericanos a enero de 1992, Ciudad de Guatemala, febrero.

(1992b): Precios que inciden on los costos de producción del sector industrial de los paises del istmo centraamericano a enero de 1992, Ciudad de Guatemala, febrero.

Warr, Peter (1989): Zonas francas industriales y política comercial, Finanzas y Desarrollo, vol. 26, № 2, Washing ton, D.C., Fondo Monetario Internacional (FMI) Banco Mundial, junio.

Willmore, Larry (1976): Direct foreign investment in Central American manufacturing, World Development, vol. 4, No 6, Nueva York, Pergamon Press Ltd., junio. 